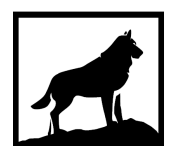

Michigan

Technological

1 8 8 5 University
Michigan Technological University

Digital Commons @ Michigan Tech

\title{
USING SHORT-TERM PROFESSIONAL DEVELOPMENT TO INCREASE SCIENCE TEACHER CONFIDENCE FOR INTEGRATING THE NGSS ENGINEERING STANDARDS
}

Janet Lalonde

Michigan Technological University, jslalond@mtu.edu

Copyright 2019 Janet Lalonde

Recommended Citation

Lalonde, Janet, "USING SHORT-TERM PROFESSIONAL DEVELOPMENT TO INCREASE SCIENCE TEACHER CONFIDENCE FOR INTEGRATING THE NGSS ENGINEERING STANDARDS", Open Access Master's Report, Michigan Technological University, 2019.

https://doi.org/10.37099/mtu.dc.etdr/931

Follow this and additional works at: https://digitalcommons.mtu.edu/etdr

Part of the Curriculum and Instruction Commons 


\title{
USING SHORT-TERM PROFESSIONAL DEVELOPMENT TO INCREASE SCIENCE TEACHER CONFIDENCE FOR INTEGRATING THE NGSS ENGINEERING STANDARDS
}

\section{By}

\author{
Janet S. LaLonde
}

\begin{abstract}
A REPORT
Submitted in partial fulfillment of the requirements for the degree of MASTER OF SCIENCE In Applied Science Education
\end{abstract}

MICHIGAN TECHNOLOGICAL UNIVERSITY 2019

(C2019 Janet S. LaLonde 
This report has been approved in partial fulfillment of the requirements for the Degree of MASTER OF SCIENCE in Applied Science Education.

\title{
Department of Cognitive and Learning Sciences
}

\author{
Report Advisor: $\quad$ Dr. Kedmon Hungwe \\ Committee Member: Dr. John Irwin \\ Committee Member: Dr. Shari Stockero \\ Department Chair: $\quad$ Dr. Susan Amato Henderson
}




\section{Table of Contents}

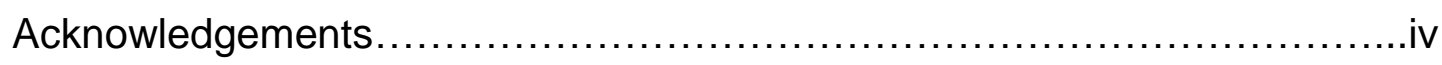

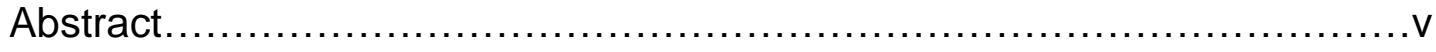

Chapter 1 - Introduction.......................................................

Chapter 2 - Literature Review.............................................

Chapter 3 - Research Design and Methods..................................10

Chapter 4 - Results....................................................... 19

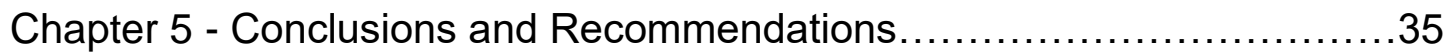

References......................................................... 43

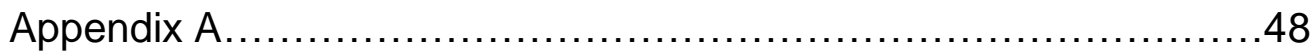

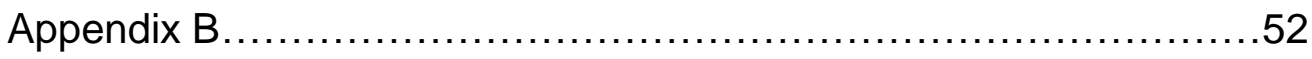

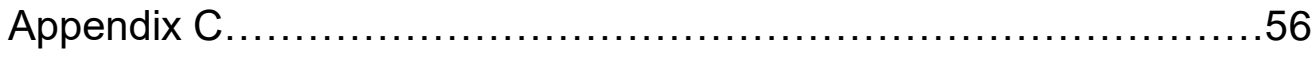

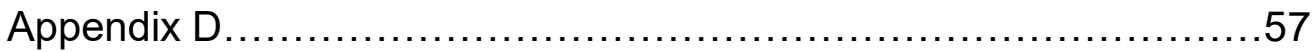

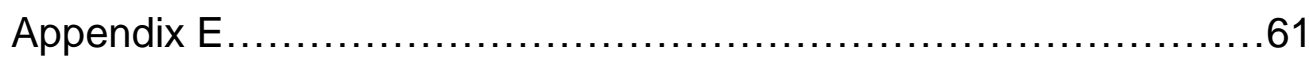




\section{Acknowledgements}

Dr. Kedmon Hungwe has my sincere appreciation for his efforts on my behalf. Not only did he agree to step in as my advisor after the research process had already begun, he immediately, gently, and efficiently set me on a much straighter course toward the successful completion of my degree. He made himself readily available to answer questions and offer timely, helpful feedback about my work. He is the epitome of a good advisor and I have reaped the benefits of his expertise.

I am also very grateful to the other members of my advisory committee,

Drs. John Irwin and Shari Stockero. Dr. Irwin was the first to inspire my interest in pursuing a master's degree from MTU. His stories and lessons about the fascinating field of engineering convinced me to take the first steps down a path that led to many adventures. Dr. Stockero offered level-headed advice and kind encouragement to an unsure 'mature' grad student. Because of her excellent teaching, the daunting prospect of doing research became far more achievable to this rookie. In doing so she played an integral part in the success of my MTU journey.

Finally, I give my deepest thanks to my family, who patiently suffered through neglect as I gave up precious time with them to work on grad class assignments, and to my GHS colleagues, who sacrificed summer recuperation time to participate in my research project. You have been an amazing support system and I appreciate you more than these few words can express. 


\begin{abstract}
Using Short-Term Professional Development to Increase Science Teacher Confidence for Integrating the NGSS Engineering Standards

By
\end{abstract}

Janet S. LaLonde

Teacher professional development has long been acknowledged as a useful tool to improve instructional methods and to increase the likelihood of successful implementation of new standards. The duration of the training is often identified as a factor that determines how successful professional development experiences can be, with the best options taking place over several days and for more than 40 hours. However, with serious limitations in time, funding, and substitute teachers, districts must often consider offering short-term professional development instead.

This case study followed a professional development experience of seven high school science teachers as they spent a day learning about the engineering standards included in the Next Generation Science Standards. The purpose was to determine if a short-term experience could increase their knowledge of the standards and their confidence to integrate them. Using pre- and post-PD surveys and individual teacher interviews, this study found that the teachers had significant increases in their knowledge of the standards and notable increases in their confidence to teach them. However, these increases did not translate into attempts to integrate the engineering standards for all but one of the teachers. Other factors were held responsible, 
but the lack of follow through prevented an opportunity to gather further evidence to support the success of the training.

The implication of these findings is that short-term professional development, if well-designed to include the other important factors that lead to success-including pertinent subject matter, opportunities for active learning, and collaboration between colleagues-can be an effective tool for districts to choose when seeking to enhance their teachers' abilities. 


\section{Chapter 1}

\section{Introduction}

When the state of Michigan adopted the Next Generation Science Standards (NGSS Lead States, 2013) in the fall of 2015, Michigan teachers were given a directive for which many of them were not prepared. One of the significant changes in the new standards is the addition of engineering practices. Very few science teachers had ever trained for, or were prepared to teach, engineering practices (Banilower et al., 2013). They were not even mentioned on the study guides for the Michigan Test for Teacher Certification (Pearson, 2019), simply because engineering had not been a topic addressed on any of the current subject matter tests required to earn certification to teach science in the state of Michigan. Not only were experienced teachers not trained in the engineering design process, the outlook was no better for new teachers. The truth still remains that Michigan science teachers are now expected to teach engineering skills, and with increasing rigor from Kindergarten to $12^{\text {th }}$ grade!

\section{Statement of the Problem}

Teacher professional development (PD) has been recognized as an important resource to support teachers to continually adapt to and keep up with changes in their profession (Reiser, 2013; Wilson, 2013). With the adoption of any new standards, professional development (PD) opportunities must be made available to train teachers on how best to address them (National 
Research Council [NRC] Framework, 2012). PD is required for educators to gain the knowledge, experience, and confidence they need to effectively teach the new standards (Allen, 2015). It is also required to maintain certification, making professional development related to integrating the engineering standards a popular choice for teachers to fulfill two needs at once.

Perhaps because it has been a relatively short time since Michigan adopted the NGSS, PD opportunities have yet to catch up with this need (State of Michigan, 2019). Even when training is available, such as the Next Generation Science Exemplar (from NGSX.org) provided through many ISDs, it is often difficult for districts to pay for registration fees and the cost of substitute teachers for all K-12 science teachers to attend several days of training. A more practical option might be for districts to provide short-term PD to their science teachers. This study was designed to investigate that option.

The objective of the study was to determine how short-term professional development experiences can increase the ability of high school science teachers to integrate engineering design practices into their core science classes. The primary source of data will be teacher self-reports of their experiences.

\section{Research Questions}

The study centers on a short-term professional development workshop and the group of science teachers who participated in it, using their self-reports about that experience to answer three research questions: 
1. In what ways, if any, did the professional development experience enhance teachers' knowledge of the NGSS engineering standards?

2. In what ways, if any, did the experience improve teachers' confidence in their capacity to implement the NGSS engineering standards?

3. How are changes in knowledge associated with changes in confidence? It is hypothesized that there will be a positive correlation between gains in knowledge as the independent variable and gains in teacher confidence as the outcome variable.

\section{Limitations of the study}

The study was based on teacher self-reports about their experiences but did not include classroom observations to assess the ways in which the PD has impacted their work. This could potentially open the study to the effects of prestige bias if the participants presumed there were certain results the researcher was hoping to have. Bias might also have come into play because the primary researcher was a colleague of the research subjects and served as the facilitator of the PD involved in the case study. While assurances were made to mitigate the possibility of biases, it would be impossible to eliminate them entirely given the close connection between the researcher and the subjects.

There was a notable time lapse (15 months) between the PD experience and the post survey and interviews that took place for this research. During that length of time, other factors may have influenced the confidence and 
knowledge levels of the teachers. In an attempt to disclose those sources of growth that may have taken place outside of the PD, teachers were asked to discuss other contributing factors during the interviews.

\section{Definition of Key Terms}

The Next Generation Science Standards are made up of Physical Science, Life Science, Earth and Space Science, and Engineering Design Performance Expectations (PE's) that students should be able to complete to demonstrate a full understanding of science. The PEs are made up of the three different dimensions of science: (a) the disciplinary core ideas, which are the scientific facts and concepts, (b) the science and engineering practices, which are the ways we actually "do" the work of science, and (c) the crosscutting concepts, which describe the methods of thinking and analyzing in science. The purpose of the standards is to provide students with the opportunity to experience how scientists actually do the work of science, with the hopeful end result of more students choosing to consider science careers. The addition of engineering standards to the science areas will ideally have the same end result - more students entering engineering fields. Even without the ideal results of more scientists and engineers, all students would be better prepared for the increasingly technical world they face when they leave school (Carnegie Commission, 2009). 


\section{Chapter 2}

\section{Literature Review}

In order to evaluate how effective a professional development (PD) experience is for raising teacher confidence to incorporate new standards, it is important to start with an understanding of what qualifies as 'effective professional development.' In the Status Report on Teacher Development in the United States, effective PD is defined simply as "that which results in improvements in teachers' knowledge and instructional practice." (Wei et al., 2009 , p. 3) It is this rather broad definition that will be the basis for judging successful PD in this study. Given such a generous qualification, one would think it would be relatively easy to develop good PD, but the frequently used, single-day, 'sit-and-git' workshop model that has been used for years has not been found to either enhance teacher knowledge or instructional practices (Stein, Smith, \& Silver, 1999).

District provided PD often involves a district-wide training event for all K12 teaching staff to attend (Little, 1993). It typically takes place in an auditorium or cafeteria, or some other room large enough to accommodate all of the teachers, and is generally led by an accomplished speaker who is 'well known in education circles' or by a group of 'education experts' of some sort, who list their impressive credentials and tell their entertaining stories while they present the latest and greatest way to educate/discipline/manage/uplift/assess students. While teachers may or may not think this is a good way to spend a 
day outside of the classroom, they seldom 'buy-in' to the ideas and leave with no more than a few notes and handouts (Davis, 2015). It is highly unlikely to promote growth in the areas of knowledge or instructional practice.

Most research to identify the essential components of the most effective professional development concludes with some version of these four elements: PD should have a specific content area focus; PD emphasis should be on the actual tasks of teaching; PD should involve meaningful collaboration between colleagues; and PD should have extended duration.

\section{Specific Content Area Focus}

One size PD does NOT fit all. Particularly when teachers are expected to learn new content area standards, it is imperative that they have the opportunity for specific training in those standards (Darling-Hammond, Hyler, and Gardner, 2017). Generalized discussions of educational theory are of little use when teachers are required to change, not just what, but how they teach. They need expert introduction to the standards, time to make sense of them and understand them fully, and they need ideas for planning how to implement them (Loucks-Horsley et al., 2010). PD training that involves a collection of teachers with the same end goal is more likely to produce successful results (Birman et al., 2000). Not only is specific content area training more effective, it is even more so when the training is about a particular curriculum that can be used to cover the standards (Mundry \& Loucks-Horsley, 1999). 


\section{Emphasis on Teaching Tasks}

While there is value in including discussions and/or presentations on educational philosophy when explaining the basis for the development of new standards, the most effective PD plans do not dwell there. Instead, they provide a balance between the reasoning behind the standards and helping teachers understand and implement the standards successfully (LoucksHorsley et al., 2010; Mundry \& Loucks-Horsley, 1999). A good PD presenter doesn't stand in front and lecture, they model best practices by getting the teacher-students involved in learning the material through active learning practicing inquiry, collaboration, peer review, and other activities they would actually use in their classrooms (Birman et al., 2000; Wei et al., 2009). After teachers are led through a well-planned lesson or two, they should have time to develop a lesson they can use fairly soon in their classrooms (Davis 2015). In a study comparing three different training methods, it was the teachers who had opportunities to learn the standards and experience the instructional practices to teach them who were most likely to take the ideas back to their classrooms (Wei et al., 2009).

\section{Collegial Collaboration}

The most effective PD involves having actual colleagues - teachers from the same school and the same department - learning and working together (Birman et al., 2000; Wei et al., 2009). Teachers demonstrate greater acceptance of new standards and methods and a deeper investment in a 
common 'game plan' they played a part in developing, especially if the district supports the training and plan (Allen \& Penuel, 2015). When teachers train collaboratively and experience the same activities together, they are more likely to develop a more common understanding of the concepts and the methods that can be used to teach them. There is also a greater likelihood that, even when they plan lessons individually, the lessons they develop will be more cohesive to one another, which is important when multiple teachers teach the same classes and are required to adhere to a similar scope and sequence (Birman et al., 2000). It also allows for more sharing of resources and ideas and the opportunity to work through issues that may be unique to the group (Wei et al., 2009). Taking peer interactions to the next level, there is also

evidence that supports the positive impact of peers teaching peers - having each teacher learn a small portion of a large body of information, then taking turns teaching the group about their 'specialty.' (Davis, 2015)

\section{Sufficient Duration}

It takes time to learn new skills (Mundry \& Loucks-Horsley, 1999). It may have taken a while, but professional development trainers have figured that out. Some of the more successful PD's are now multiple sessions spread throughout a school year or offered for an extended period during the summer. There is a direct correlation between the time spent in PD and successful implementation of new standards (Birman et al., 2000; Davis, 2015; Wei et al., 2009). There is also a positive relationship between the amount of 
time teachers are engaged in PD on particular standards and how prepared they feel to teach the content in the standards (Heck et al., 2008). It still remains an issue that PD that takes place over extended time periods requires a more significant financial commitment from the district and time out of the classroom (or summer recuperation period) for the teachers. It is ideal to have more time, but it doesn't always work out for those involved. 


\section{Chapter 3}

\section{Methodology}

A single retrospective case study was conducted to research the effectiveness of a short-term PD training for increasing teachers' knowledge of the NGSS engineering design standards and their confidence to integrate them into their instruction. The study followed the experiences of a group of Greenville High School science teachers who participated in a one-day PD designed to introduce and familiarize them with the NGSS Engineering Technology and the Application of Science (ETS) standards. While the results from one case study cannot be generalized to other situations, it can provide some insight into how events played out in one school, which may benefit those considering the same course of action for their own high school science staff (Kennedy, 1979).

The Engineering PD took place at Greenville High School, a semi-rural school in west Michigan, on May 17, 2018. The members of the science department met in a classroom at the start of the school day, beginning with a session to "unpack the standards." During this part of the day teachers were supplied with printouts of the four ETS Performance Expectations (PEs), including the companion documents from the NGSS website (see Appendix A), along with copies of the Framework for K-12 Science Education (NRC, 2012) chapter pertaining to the engineering standards. The second session involved a "Learning Lab." The teachers observed an Honors Freshman Physics class 
as they engaged in an activity that demonstrated one way to accomplish one of the performance expectations (HS-ETS1-3). Following the learning lab, the teachers discussed their observations and reflections. Session 3 involved working with a partner to search for online simulations that could be used to address the 4th ETS PE, which requires students to test the effect of different solutions to a real-world problem. Finally, in Session 4, the teachers examined a Biofuel STEM activity kit, which had been purchased from a science education supply company. Their goal was to determine if the activities provided in the kit could be used for potential engineering projects in their particular core science classes. The lesson plan for the PD day can be found in Appendix B.

\section{Participants}

The participants were seven (7) science teachers from Greenville High School. The primary core classes they teach are Biology and Chemistry, as the only Physics teacher was leading the PD. The group was made up of four males and three females, with years of teaching experience at GHS ranging from 10 to 24 years.

\section{Context}

This particular group of science teachers have been in the first few years of aligning their core science courses to fully incorporate all of the Next Generation Science Standards. In anticipation of the adoption of NGSS they have previously been through several full days of training (spanning over two 
school years) on the $\mathrm{QPOE}^{2}$ (Question-Predict-Observe-Explain-Evaluate) model, a method for teaching science through inquiry developed by the Van Andel Education Institute in Grand Rapids, MI. They have also undergone NGSX training through the nearby Kent Intermediate School District, which focused primarily on how to use phenomenon to promote student interest and show connections between concepts. In an effort to teach "all standards to all students," per NGSS dictate, the department has made changes to its course sequences and requirements, beginning with the freshmen class in the fall of 2018. Starting the new system with freshmen while keeping the old system in place for 10th - 12th graders has made for a challenging year, as has attempting to blend the Earth Science standards into their courses. Some teachers were also required to take on extra sections of classes they seldom teach in order to work the 'old system' out while the 'new system' comes in.

\section{Instruments}

Pre-Survey (see Appendix C): At the beginning of the PD day, the teachers were asked to complete a short survey. The questionnaire requested information about how knowledgeable they felt about the NGSS engineering standards, and how confident they felt about integrating these standards into their core science classes. Two Likert scale style questions invited teachers to rate themselves on a scale from 0 (low to no confidence and/or knowledge) to 5 (high confidence and/or knowledge). In addition, following each of these 
questions a space was provided for them to explain their selections further if they chose to do so.

Post-Survey (See Appendix D): The Post-PD survey, which was administered in the summer of 2019 , included the same two Likert scale style questions as the Pre-PD survey, asking teachers to rate their confidence and knowledge levels on the 0 to 5 scale again. The Pre-PD and Post-PD ratings for each teacher were compared, providing quantitative data to determine the effectiveness of the PD. The post survey also included questions about each of the sessions in the PD training, asking teachers to evaluate how well, if at all, they fulfilled their purpose to increase their confidence and knowledge levels. A survey question also asked teachers to indicate whether or not any implementation efforts had taken place in the two semesters since the PD.

Semi-structured Interviews (see Appendix E): Each teacher took part in an interview following the completion of their Post-PD survey. During the interviews, which were conducted individually and lasted from 15 to 42 minutes, teachers were asked to explain and expand upon their survey responses regarding the ratings of their confidence and knowledge levels. They were also asked to reflect upon their PD day experience in general. The participants were given an opportunity to elaborate upon their 'yes or no' responses to the PostPD survey question about implementation. If they answered 'yes,' they were asked to describe the engineering activities they ventured to try and share about the experience. If they answered ' $n o$ ' to the implementation question, 
they were asked what kept them from trying to undertake any engineering projects with their classes. In addition, the teachers were encouraged to comment on any additions to their 'engineering arsenal' that took place since the PD - whether they had received any further training, done any helpful research, or acquired supplemental engineering-related resources since the PD. The interviews provided a wealth of qualitative data.

\section{Data Analysis Procedures}

The Pre- and Post-PD survey questions required participants to choose a numeric value, from 0 to 5 , to coincide with the most accurate description of their confidence and knowledge levels for implementing the engineering standards. An increase in values from before to after the PD would indicate that the PD, or possibly some other experience or training during the intervening time, contributed to the improved confidence and knowledge levels. If there were no increase in the ratings, then neither the PD, nor any other experience in the interim, was effective for increasing their knowledge and/or confidence. Given the unusually long time interval between the Pre- and PostPD surveys, it was necessary to determine whether or not the teachers had experienced additional training or had acquired information separate from the PD that could have affected their confidence and knowledge levels for the engineering standards. An interview question regarding any such experiences was included for the purpose of revealing these extenuating factors. 
Numeric survey data was compiled using a Google spreadsheet. This data included the $0-5$ ratings individual teachers gave themselves to indicate their confidence and knowledge levels before and after the PD. Question number 1 on both the pre-PD survey and the post-PD survey provide evidence for the teacher confidence question. Bar graphs were constructed for each individual teacher to reveal any differences in their Pre- and Post-PD survey results. The graphs also revealed whether a trend existed within the group. A second bar graph was made for each teacher to display the evidence relating to the knowledge question, information that was pulled from the responses to question 2 on both the pre-PD and on the post-PD survey. Again, the graph revealed individual changes as well as any group trends in increases, decreases, or unchanging knowledge levels.

Statistical analysis included finding the group mean of the self-ratings for confidence before and after the PD and the same for their knowledge selfratings. These were used to show whether or not a trend of change in individual scores produced the same trend in the group scores. A positive change in the group mean contributes evidence in favor of the effectiveness of the PD on the group overall, whereas a negative change does the opposite. The mean was also used to determine the standard deviation (STDEV) from any existing group trend. The larger the STDEV in the ratings before the PD the greater the individual teacher differences in confidence and knowledge levels as they entered the PD experience. The larger the STDEV after the PD, the greater 
the discrepancy in individual teacher PD experiences. In contrast, a smaller STDEV before and after the PD implies that teacher ratings were similar to one another before the training, and that the PD had a comparable effectiveness for each of them.

The mode for the confidence and knowledge ratings was used to identify how many individuals placed themselves at the same level of readiness to integrate the engineering standards both before and after the PD. It was also used to highlight the number of teachers who rated themselves significantly higher or lower than the others in either category.

Another possibility to consider was that there might have been a direct link between the teachers' confidence and knowledge levels. Does teacher confidence naturally increase as their knowledge about a subject increases? To determine if this is a consideration, the average changes in confidence and knowledge levels of the participants were analyzed to determine if any correlation exists between them. A positive correlation coefficient indicates that there is a relationship evident between the variables, with a maximum value of +1 indicating a 'perfect' direct correlation. A negative correlation coefficient, with a minimum of -1 , indicates an equally strong inverse correlation. A correlation coefficient of 0 means there is no correlation evident between the variables.

Individual teacher Post PD Interviews were transcribed and coded to identify and assemble all of the comments pertaining to 1) feelings about PD in 
general, 2) feelings about the NGSS in general, 3) occurrences that affected confidence, and 4) occurrences that affected knowledge. The collected qualitative information has been used to construct a thick description of the teachers' PD experience.

\section{Researcher-Participant Relations}

This PD was led by myself, as I am considered to be the 'resident relative expert' on engineering design. I gained this distinction because I have a genuine interest in engineering that started when I was coaching students in Science Olympiad building events (long before the NGSS standards were introduced) and expanded when I transplanted versions of those events into my Physics lab activities. I found training to support my interest by taking an engineering-related summer class at MTU to earn credit for certificate renewal, and it was that class (ENG 5200) that introduced me to the Master of Applied Science program at Michigan Tech. By the time I was half way through the program and had completed my internship with our city engineer, I had already been asked several times by my science colleagues to offer them some sort of training in the engineering standards, as none of our previous training experiences had provided it, and there were no other opportunities on the horizon that would. Their voices were joined by that of the assistant superintendent and a year or so later, the PD came to be.

\section{Ethical Considerations}


Each of the teachers involved in the PD training initially gave verbal consent to take part in this research project, and they were also given an Informed Consent Form before being asked to complete the Post-PD survey. Only data from those who signed their approval was used in this study. There was no anticipated risk for the teachers involved, as the study was focused on whether or not the PD was effective, not on the behavior or performance of the participants. However, to protect their privacy, each teacher was referred to using numbers not associated with their names, ages, or any other distinguishable characteristic (ex. T1, T2, T3, etc.). The participants knew their involvement was voluntary and that they were able to withdraw at any time. At no time during or after the study will their actual identities be revealed. For the record, every participant gave consent for their information to be included in the study. 


\section{Chapter 4}

\section{Results, Analysis \& Discussion}

\section{Introduction}

This study was to determine the effectiveness of short-term teacher professional development for helping teachers prepare to integrate new standards, specifically the engineering standards included in the Next Generation Science Standards. To evaluate the effectiveness of the PD a group of Science teachers responded to questions related to two areas of focus before and after the PD experience, 1) how confident they felt about integrating the standards, and 2) how knowledgeable they felt about the standards.

\section{Background of Participants}

The group of seven teachers involved in this study were no strangers to PD. The least experienced of them had been teaching for more than 10 years in a district that offers 4 to 5 mandatory PD days each year, along with funding periodic out-of-district opportunities. The most senior teacher, with over 30 years in the classroom, had encountered well over 125 professional development trainings. This is sufficient PD background to consider these teachers able to evaluate the effectiveness of PD for improving their knowledge and/or instructional practice. When asked to rate their overall feelings about PD effectiveness on a scale of $1-10$ (10 being the most positive), the average rating was 4.4 , with six of the seven teachers scoring PD effectiveness at a 5 
or lower. This is a clear indication that, based on the experience of this group of teachers, most PD was not considered to be very effective.

When given an opportunity to comment further on this low opinion during the follow up interview, there was a common sentiment among the teachers (mentioned by five participants) that the PD provided by the school district tended to be too general to be useful. Because it usually involves an entire staff - or at least an entire building staff - it was not specific enough to address topics that could have an immediate impact on pedagogy. In some cases, presenters would show examples of their method or technique applied in language arts or math classes - but leave other subject areas hanging to create their own. The teachers were especially not keen on PD centered around district initiatives that could be referred to as "momentary fads." The impact of PD initiatives was sometimes limited by technical difficulties or poor planning.

When teachers were asked to describe the features of effective PD, the most commonly cited factor was that it should be subject matter related. Teachers wanted to learn new ideas for teaching their subject matter - ideas they could implement after the training. Five of the seven teachers interviewed identified the most positive PD experiences they had - AP Summer Institutes, Michigan Science Teachers Association Conferences, Van Andel Institute QPOE ${ }^{2}$ Community of Practice, NGSX - all of which were related to science-specific training. Each of those training opportunities covered a 
different facet of teaching, AP classes, inquiry, modeling, etc. - but it was all about science.

The PD experience used for this study was based in particular on the new engineering performance expectations, but it also involved the language and format of the NGSS in general. The teachers' opinions of the NGSS were more positive than that of $\mathrm{PD}$, with an average rating of 5.6 out of 10 . Only two survey respondents gave a rating under 5 . Interview comments about the NGSS ranged from claims that it has improved how we teach science and increased student engagement and interaction to the comment that it is ambiguous and confusing. One theme that surfaced in four different teacher's comments was that the lack of a supporting curriculum for NGSS which was quite frustrating. Only two of these teachers were comfortable writing new curriculum. It's one thing to take an existing curriculum and improve upon it, it's quite another to start from scratch with standards, which takes an enormous commitment of time and energy. This is one reason they gave for the admittedly slow implementation process for all of the required standards, including those involving engineering.

The teachers' feelings toward attending the engineering standards PD was assessed. The average rating was a 9.1 out of a possible 10, indicating an open, if not eager, audience for the training. Four of the seven teachers even noted that they had requested, even pushed for, the PD to take place to help 
them get ready to integrate the new engineering standards, and just as many teachers rated their feelings about attending the PD at a 10 out of 10 .

Impact of PD on Teachers' Confidence

Was the PD effective at raising the confidence of the teachers to integrate the engineering standards? According to the participants, it was moderately effective. However, it is important to consider the initial level of confidence before the PD took place. On a scale of 0 to 5 , with 0 being not confident and 5 being very confident, six of the seven teachers rated themselves at a 2 or lower on the pre-PD survey, with 2 being the mode. This below average rating is in spite of two circumstances that should have affected teacher confidence in a positive direction. First, a certain degree of confidence comes from having more than 10 years of teaching experience (Bilanich, 2019), which is true for each of these teachers. Second, previously acquired training for the NGSS provided another confidence-building opportunity (Skills You Need, 2019), again something they had all gone through. Given these advantages, an average (and most common) confidence rating of 2 was a low starting point. At best, most of the teachers felt only 'somewhat confident' about taking on the integration of the engineering standards, as shown in Figure 4-1. 
Figure 4-1 Teacher Confidence for Implementing NGSS ETS

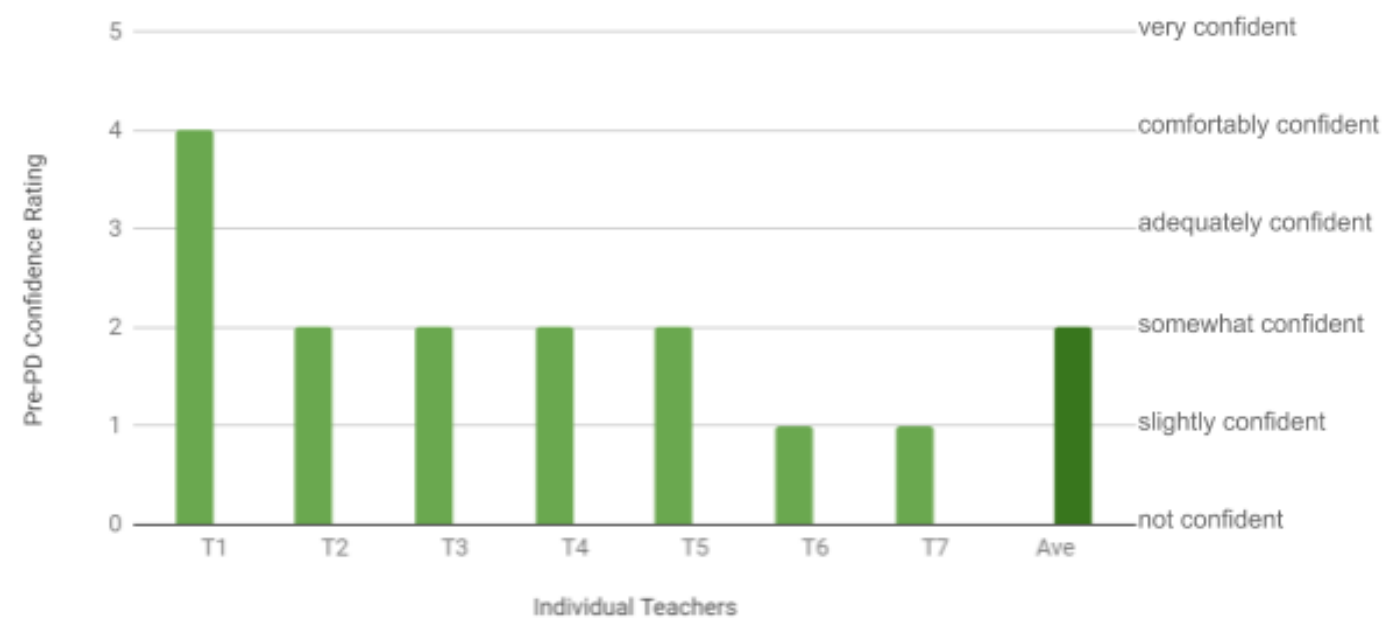

Only one teacher, identified as T1 in Figure 4-1, gave themselves a 'comfortably confident' rating, which they later stated, in the post-PD interview, was the result of a "personality flaw." They elaborated on this by explaining that their default setting tends to be to go into things with the belief that they are better than they really are and know more than they really know. Only after actually doing things do they realize where their abilities truly stand in the scheme of things, which tends to lower their confidence to a more realistic level. This self-professed 'over confidence' is evident on the graph for T1 (in Figure 4-2), where the pre-PD and post-PD survey comparison shows that they were the only person who showed a decrease in confidence.

The teachers were asked to rate their comfort level on the first question of the pre-PD survey, and were asked again on question \#1 of the post-PD survey, which was "Following the PD, how would you rate your comfort level 
for integrating the engineering (ETS) standards into your science lessons?" The responses revealed that, with the exception of $\mathrm{T} 1$, confidence levels increased, sometimes significantly. In Figure 4-2 below, post-PD ratings have been added to compare with the pre-PD data for each teacher. The average confidence level of the group rose from a 2 to a 3.3, with a mode of 3 . A 3 indicates an "adequately confident" rating, which is an improvement, but still below the 'comfortably confident' level at which only two of the teachers felt able to place themselves.

\section{4 - 2 Survey Results for Teacher Confidence Levels}

5

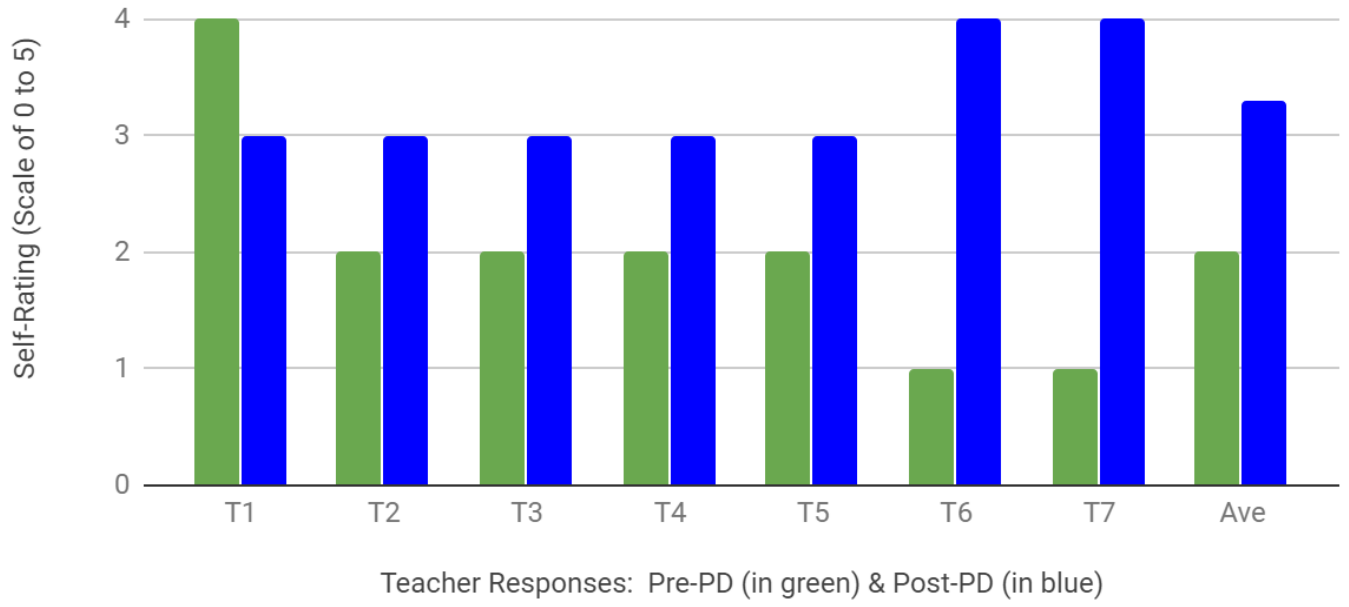

The standard deviation was reduced by half, from a 1.0 before the PD to a 0.5 after the PD. T1 was an outlier in the pre-assessment, with a high confidence rating. It appears that T1 realized that they weren't as confident 
about integrating the standards as they had originally thought. This was later confirmed during the follow-up interview.

When asked to expand, during the interviews, on how the PD training helped them gain confidence, the teachers gave a variety of responses. Several of them commented that the initial 'unpacking the standards' session, where they were given time to read through and then discuss the Framework narrative on the engineering standards, was quite helpful simply because they hadn't made the time to read through them before. T3 stated "I think just not having had the chance to unpack those, reading through them made me realize the engineering wasn't what I thought it would be." They universally agreed that reading through the Framework explanation can help give teachers a broader perspective of what is expected for the standards, the wording of which can sometimes be vague and hard to understand. Teachers generally have long to-do lists, and spending time on the engineering standards never had top priority until the PD. This was the case for T2, who during the interview shared "I think just being forced, for the lack of a better word, to actually just sit there and read it - because sometimes you intend to do things, and you know it's there, and you know where to find it, but you don't take the time...there's more important things, and you push it aside." When it came to working on standards, they identified their core area standards as first on the list of priorities, the earth science standards as second, 
and the engineering standards third. Most teachers had not even gotten through the priority core area standards prior to the PD.

Another common thread related to increasing their confidence was that the PD helped them realize the engineering requirements of the NGSS aren't as technical or complex as they originally feared. Not having been through any engineering training whatsoever, some of the teachers assumed that the standards would be far too difficult for them to learn and understand without extensive training and therefore assumed it would be almost impossible - and very unlikely - for them to integrate them into their core science classes. Fortunately, as a result of the PD, they realized this was not the case. Seeing it in action was a huge help. T3, for example, stated "engineering is not as daunting as I feared it would be, kids are capable of doing it." During the interviews they shared that, having just read through the standards, and then being able to watch the students go through the activities that clearly fit the standards - "it was like the target had been identified for us and then we could see the students making a direct hit. The discourse and coming to a consensus, the consideration of criteria, the evaluation of possible solutions it was all modeled for us successfully (T5)." T7, stated "I could see myself taking the students through that process."

In the third session of the PD teachers were paired up by subject matter, challenged to choose one possible engineering project idea, then given time to search for online simulations that students could use to "model the impact of 
proposed solutions to a complex real-world problem with numerous criteria and constraints..." (NGSS, 2013). On the actual PD day teachers had mixed results finding suitable simulations, and the search was somewhat overwhelming, which had little value in raising their confidence. However, the lack of success prompted some of the more tech-savvy department members to look for a better solution, resulting in a school subscription to Gizmos Math \& Science Simulations (Explorelearning, 2019). Two of the teachers attributed an increase in confidence to a day-long training by the Gizmos staff, during which they were able to find applicable simulations for some of the engineering projects they came up with.

In summary, though the initial confidence ratings were quite low, every teacher placed themselves at or above the "adequately confident" level on the post-PD survey. The average confidence rating increased from 2 to 3.3, with a standard deviation of 0.49 . T4 responded that even the best training would only be able to increase their confidence by a small amount, "I think a lot of that ...comes with just trying stuff in my classroom." It would require actually doing some engineering activities with students and learning by trial and error to move them to the "very confident" level. T7 thought somewhat differently, remarking "I have more knowledge, which makes me feel more confident," an opinion which was also shared by T6. 


\section{Impact of PD on Teachers' Knowledge}

The second indicator used to gauge the effectiveness of this short-term PD experience was whether or not it was able to improve how knowledgeable the teachers felt about the engineering standards. The pre-PD surveys revealed that most of the teachers felt they were only "somewhat knowledgeable" or less at the time, with a Pre-PD mode of 1 (see Figure 4-3). Only two teachers indicated they felt they were "adequately knowledgeable." An average of 1.9 is a low starting point, but the mode of 1 indicated there was much room for improvement. A STDEV of 0.9 indicated that there was a relatively small ( 1.2 being typical) departure from the average for each teacher rating.

\section{4-3 Pre-PD Survey Results for Knowledge Levels}

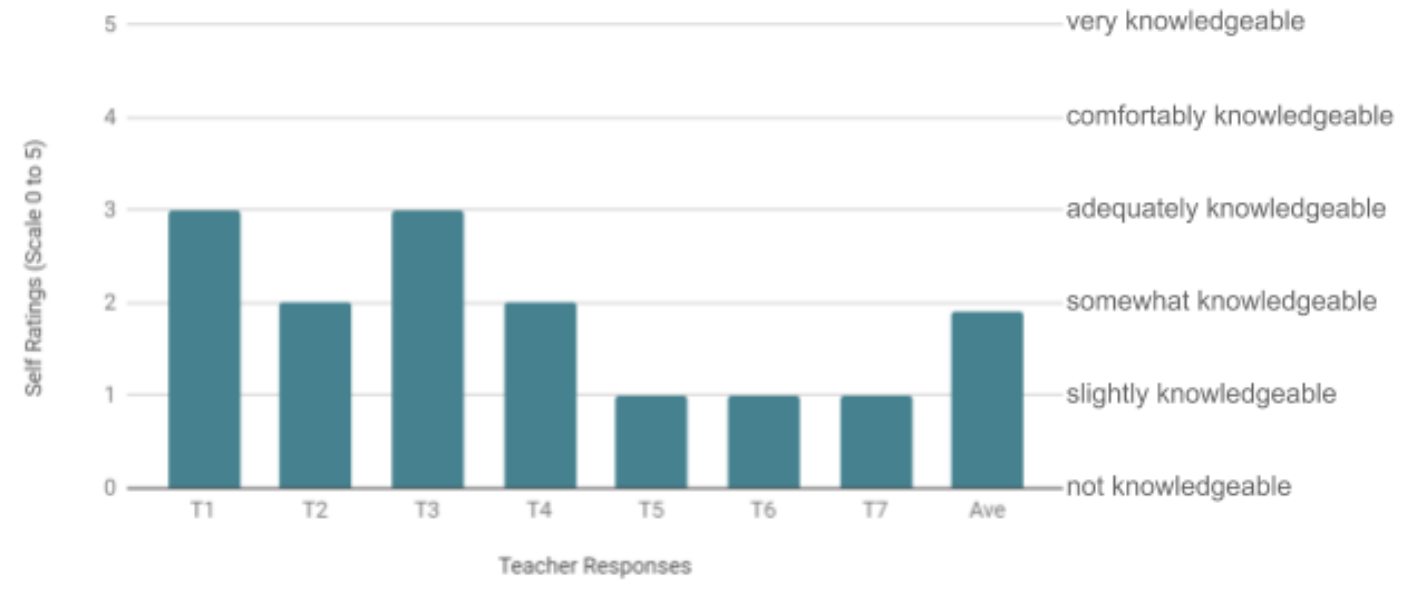

As T2 pointed out during their interview, "I've never been trained to be an engineering teacher." This teacher was initially taken aback at the idea of being required to include engineering projects in their science curriculum and did not see how the two of them could go together without glaring 
incongruities. In contrast, one of the higher scoring teachers shared that they had a sentimental interest in engineering because their grandfather was an engineer in the uranium mines. This prompted them to do some independent learning about engineering. The others were not so intrinsically motivated.

After the PD took place teachers indicated (in their response to question number two) they were much more secure in their knowledge level, with a universal increase in ratings, as seen in Figure 4-4. Four of the seven teachers felt they had risen to the point of being comfortably knowledgeable as a result of the PD, increasing the mode from 1 to 4 . One teacher felt that, with a little classroom practice, he could easily see himself move to a rating of 5 - an impressive change from the 1 he gave himself before the training. The average rating of the teacher group rose from 1.9 to 3.6 as a result of the PD experience, and a STDEV of 0.5 shows that there was little variation from teacher to teacher in their improved rating.

\section{4-4 Survey Results for Teacher Knowledge Levels}

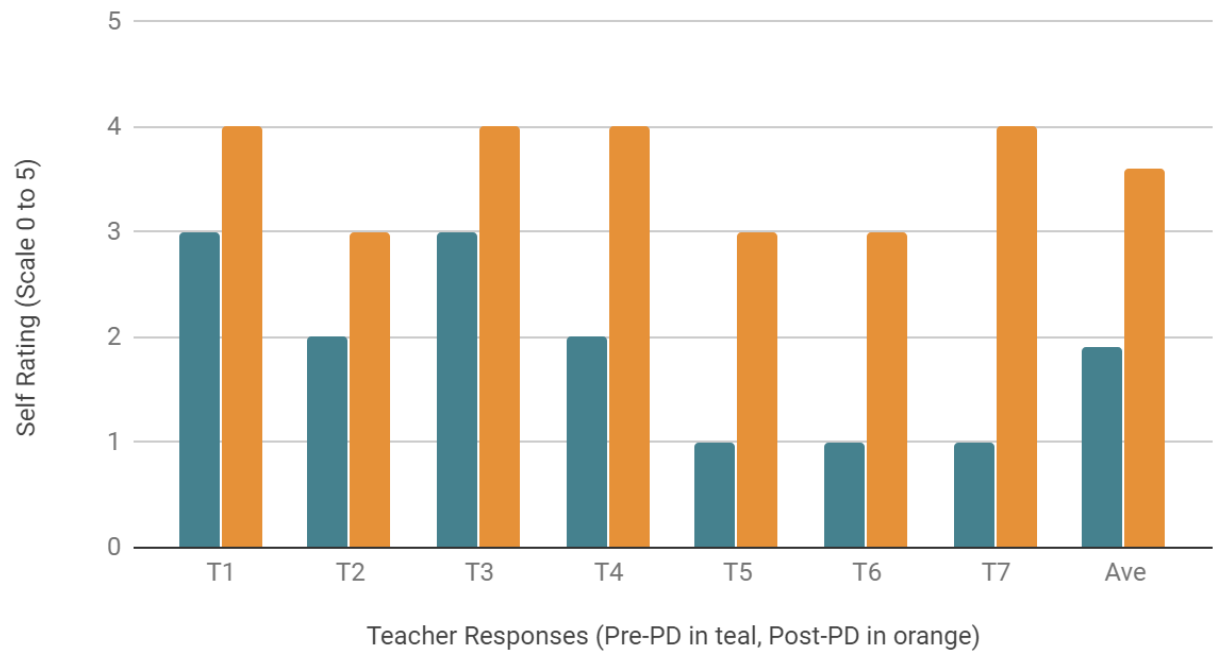


Much of the credit for the increase in ratings was traced to the fact that this was the first opportunity the teachers had for designated time to spend working on the engineering standards together. Just "being forced" (in the words of T2) by the scheduled PD day to read about and discuss and observe students in action - with all the activities centered on engineering, allowed the teachers to learn about it. For three of the participants, it meant recognizing that some of the activities they've already done in their classes could, with relatively minor changes, become credible choices to use for engineering projects. For others, it showed them that the engineering requirements were not so complex or time consuming to make them unmanageable. One teacher, T5, said he benefited in particular from the "piece by piece" structure of the PD that allowed him time to "process and synthesize the information."

\section{Relationship Between Teachers' Gains in Knowledge and Confidence}

It was hypothesized that teachers' gains in knowledge would be positively correlated with gains in confidence to implement the engineering standards. To test the hypothesis, a correlation test procedure was run with gain in knowledge as the independent variable and gain in confidence as the dependent variable. Figure 4-5 indicates the graphical result. Data from all seven teachers is shown, however, in two examples they occupy the same coordinate, giving the appearance that only five were included. The line of best fit indicates a linear, positive relation, with confidence increasing as a result of 
knowledge gains. The data also indicates one clear outlier. As discussed earlier, the outlier was T1.

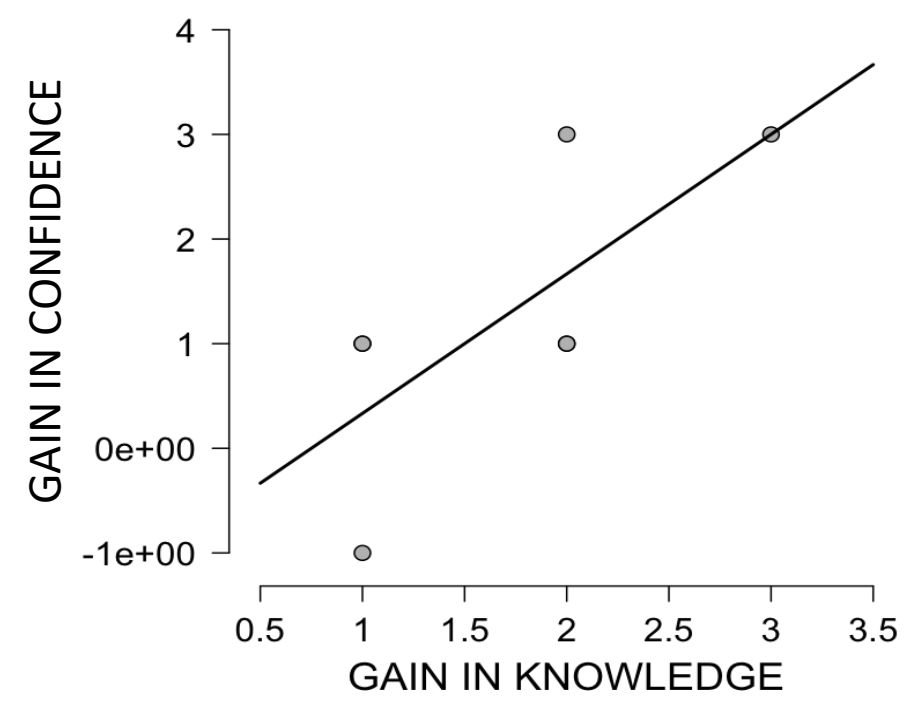

Figure 4-5: Plot of gain in knowledge vs gains in confidence

To assess if the gains in confidence were statistically significant, the Spearman correlation coefficient was generated. Significance was set at the standard $\mathrm{P}<0.05$ level. The output is shown in Figure 4.6 below.

Figure 4.6 Pearson Correlations

\begin{tabular}{lrrr} 
& & Pearson's $\mathbf{r}$ & $\mathbf{p}$ \\
\hline GAIN IN KNOWLEDGE & - GAIN IN CONFIDENCE & 0.730 & 0.062
\end{tabular}

${ }^{*} p<.05,{ }^{* *} p<.01,{ }^{* * *} p<.001$

The correlation was 0.730 , with $p=0.062$, which is not statistically significant. It is likely that a significant outcome would be found with a larger sample. The smaller the sample, the greater the impact of the outliers, and Type II error. 
Type 2 errors happen when a significant impact is not detected. One way around the problem is to increase the sample. Another way is to replicate the intervention and see if there is a pattern of gains. Overall, the results do offer encouragement that the interventions were effective.

Evidence for the effectiveness of the PD for raising teacher confidence and knowledge levels would be specific examples of how the teachers successfully integrated engineering projects into their core science classes. The interviews revealed that only one of the seven teachers (T6) had been able to implement what they learned, adding two engineering-related activities to their lesson plans in the semester after the PD. One activity was related to regulating airbag inflation (AAAS, 2019); the other guided students through designing the best water-shedding windshield treatments (TeachEngineering, 2018). After trying out these activities for the first time, the teacher could see that, with a little work on their part, they could transform them into engineering projects that fit nicely into his Chemistry 2 curriculum. They plan to revise them and use them again.

Other teachers did not fare so well in their implementation goals. When asked to elaborate about why they did not carry through, the most common response, given by four of the teachers, was "time." Due to a recent realignment of course sequence and requirements, along with the adoption of the NGSS, teachers felt they were too busy (and stressed) just developing their core curriculum lessons and searching for phenomenon on which to base 
them. The engineering standards were not their top priority. Several teachers acknowledged that they would benefit from further PD on the subject, suggesting that they would like to see more examples of students in action in a Learning Lab setting. They also mentioned that they would be more likely to be able to integrate an engineering project into their core curriculum if an appropriate one was 'handed to them' as part of a further PD. This would save them the time of searching for or developing one themselves. The PD time could be used to go through the project themselves to get firsthand experience that would increase their knowledge and confidence even further, and ultimately add to their enthusiasm for the project.

One teacher, T2, was in a unique position in the year following the PD they didn't teach any core classes. They also felt that their elective classes were outside of the scope of the NGSS and therefore they were not compelled to implement any of the standards. However, to their credit, they did discover (online) several engineering-related activities that would enrich their Anatomy \& Physiology curriculum. They also recognized the value in having as many classes as possible covering the standards. This curricular overlap could be another topic for discussion at a follow up short-term PD, giving the teachers more time for the "meaningful collaboration between colleagues" that research shows is an important component of effective PD (Birman et al., 2000; Wei et al., 2009). 
A final obstacle blocking implementation was the struggle to find relevant engineering activities for a basic level Chemistry 1 course. This teacher, T4, was excited about including engineering activities but was unable to find ideas that didn't involve chemistry concepts that were far more advanced than she covers in her freshman classes. She, along with several colleagues, proposed that it would increase their knowledge and confidence even further if there were a follow up engineering standards PD that included going through specific examples of projects that could be used in each core class. 


\section{Chapter 5}

\section{Conclusions and Recommendations}

\section{Summary}

This study was carried out to investigate whether or not a short-term PD could effectively increase science teachers' knowledge and confidence to integrate the NGSS engineering standards. The case study followed the experiences of seven high school science teachers who participated in professional development training during a single, day-long workshop that took place at their school and was led by a colleague with experience and training in engineering design. All seven teachers involved in the PD indicated that their knowledge of the engineering standards increased as a result of the PD.

Six of the seven teachers expressed that they also felt their confidence for implementing the standards increased, though not as much as their knowledge. The results of Pre- and Post-PD surveys, as well as the teacher testimonials shared during individual interviews, attest to the possibility that using short-term PD to train teachers is a viable approach.

\section{Evaluating the Proposed Solution}

Much of the research on the subject of teacher professional development concludes that one of the factors that affects success is the duration of the training. PD that takes place over several days and for at least 40 hours has been found to be the most effective at changing teachers' instructional practice (Birman et al., 2000; Davis, 2015; Wei et al., 
2009). However, such prolonged training opportunities are not always available, affordable, or desirable for districts and/or teachers. Short-term PD, on the other hand, is less costly for the district, requires less time commitment from the teachers, and does not require inconvenient travel. But can short-term PD be used to effectively train teachers? The results of this study suggest that it might. Extended duration is not the only factor that determines PD effectiveness, and it may not be the most important one (Lauer et. al, 2014). Because of this, it may be possible to make up for limited training time by successfully incorporating the other elements of effective PD.

The teachers involved in this study have had abundant experience with PD, most of which they criticized as being unproductive and a waste of time. This poor evaluation of PD, however, was not attributed to the training being short term. It was due to the generalized topics being covered and the methods used to cover them. In contrast, the PD involved in this study was considered by all of the participants to be effective and purposeful. When given the opportunity to rate the quality of the PD on a scale from 1 to 10 , the group produced a favorable average of 9.1 , more than double the 4.4 average they gave to PD overall. Their vigorously positive ratings for this particular shortterm PD for ongoing teacher training also came with compelling evidence for how to make it successful.

The focus PD for this case study was subject-matter based. The PD was for science teachers and it was related to science standards. Five of the seven 
teachers involved in the study stated that the most effective PD experiences they have had have been subject-matter based. Two of them mentioned that PD is more helpful when they don't have to go through the frustrating process of trying to figure out how a particular math or language arts example, given during a generalized PD, could apply to science.

The PD plan included time for collaboration between colleagues. The teachers learned, observed, brainstormed, and planned with the same coworkers they will be joining forces with in PLCs and department meetings in the school years to come. Some of them will even be teaching the same classes, using the same lessons, and giving the same assessments. "We found some pretty good ideas and [realized] how we could use some activities we were already doing with some minor changes (T3)." When asked how well the collaboration session increased their confidence and knowledge levels on a scale from 0 to 5 , with zero being 'not at all' and 5 being 'significantly,' the average of the teacher responses was 3.6 and 3.7, respectively.

The PD incorporated an opportunity for teachers to observe an actual example of how the material could be addressed with students. The learning lab allowed them to see successful implementation of the standards in action. T2 commented, "I'm seeing kids in action. To me, that's some of the best PD." T7 shared, "Just watching that in action was pretty helpful, just watching the students go through the process." An alternative to this "live action' Learning Lab would be to watch a video of students taking part in such 
an activity or to read or hear a report about how the lesson transpired and see the artifacts of the student activity. The Learning Lab session of the PD earned the highest marks for effectiveness from the teachers, who credited the session with an average rating of 4 and 4.1 out of a maximum 5 for how well it increased confidence and knowledge levels.

The goals of the short-term PD were very focused, in keeping with the limited time frame. The purpose of the case study PD was to introduce the NGSS engineering standards and to help teachers learn ways to integrate them into their science curriculums. It was not about the NGSS in general, which would be a completely unreasonable undertaking for a one-day PD; nor was it reduced only to the level of a single core subject area, still too much information to cover. This PD honed in on the four high school engineering design performance expectations, narrowing the topic to a small enough field of information to allow the facilitator to use several different approaches, all aimed at the same target topic. The best PD plans are "highly focused" according to T4. This gave the teachers more opportunity to deepen their understanding, rather than skimming the surface of too much information.

While the teacher participants universally felt that this short-term PD was a worthwhile experience, the fact remains that there was little attempt by most of them to implement the standards in the year following the PD. In addition, teacher confidence was increased, but not enough for most of the 
teachers to rate themselves as "comfortably confident," a level which could potentially be reached with additional training.

\section{Limitations}

With fewer than $3 \%$ of all science teachers trained and/or experienced in engineering design, it would also be difficult for most districts to provide a "local expert" to lead an on-site PD. They could consider sending one teacher for training and then having them impart what they have learned to their colleagues, but this might also be challenging, considering the lack of availability of training and that it would take more than one training to raise someone to the level of local 'expert.'

The teachers involved in this study had previously received training on how to deal with the changing expectations that came with the NGSS. They were also very interested in learning about the engineering standards. Not every science teacher would be so prepared or so interested in the PD topic, and therefore might not have given such a positive evaluation.

Finally, the district authorities supported the request from the teachers for the training on the engineering standards, trusted the expertise of one of their own teachers to lead it, released the teachers for the PD day, and provided the required number of substitutes to cover for them. Not every district would be willing to do so. 


\section{Recommendations}

It has been well supported (Mundry \& Loucks-Horsley, 1999) that professional development increases the likelihood of successful implementation of new standards and improves instructional practice. However, the assertion that PD must be long term in order to be effective has not been supported by this case study, nor by other notable PDrelated research. Lauer et. al (2014) established that the content of teacher PD had a far greater impact on how beneficial it ultimately was for students than the duration of the PD did. This means districts need not hesitate to provide the less expensive and more convenient short-term PD opportunities for teachers, as long as they also heed the additional findings. Primarily, the PD content must be highly pertinent to the needs of the teachers involved, it must not be too complex for a limited time period, and it must give them opportunities for active learning and working and planning with colleagues.

As indicated by the teachers in this case study, generalized PD is not effective. While it is likely very difficult to find a single topic that is meaningful for all K-12 teachers, there are a variety of worthwhile topics that could be addressed if multiple sessions were offered during a single PD event - subject matter standards, classroom technology applications, and specialized instructional methods to name a few. Taking advantage of local leadership, allowing those with expertise and experience to share what they know with 
colleagues, opens the possibilities up even more to offer attractive choices for teachers.

Several of the teachers involved in the case study suggested that the solution to the issues of low implementation and ratings of not quite 'comfortably confident' could be found by having another short-term PD. They also suggested the kind of activities that would be best for the agenda, which coincide perfectly with the recommendations for this study. They want to hear about engineering projects appropriate for each core science class (highly pertinent content with limited complexity); they want more time to work with their PLC colleagues; and they want a chance to observe at least one more learning lab (active learning).

\section{Implications}

The success of the PD involved in this case study provided sufficient evidence to support the idea that short term PD has a place in the greater scheme of continuing teacher education. The data shows that it effectively increased the knowledge and confidence of the teachers. It was also wellreceived by the participants and produced requests for more of the same opportunities for PD.

The successful implementation of lessons involving the engineering standards by one teacher also supported the feasibility of short-term PD, but the lack of implementation attempts by the remaining six teachers strongly 
suggests that additional follow up training, mentoring, or other supports need to be provided to produce usable evidence that there has been a change in instructional practice. 


\section{References}

AAAS, 2019. It's a crash test, dummy. Retrieved from:

\section{http://sciencenetlinks.com/lessons/its-a-crash-test-dummy/}

Allen, C.C. \& Penuel, W.R. (2014). Studying teachers' sensemaking to investigate teachers' responses to professional development focused on new standards. Journal of Teacher Education, 66(2), 136-149.

Banilower, E. R., Smith, P. S., Weiss, I. R., Malzahn, K. A., Campbell, K. M., \& Weis, A.M. (2013). Report of the 2012 national survey of science and mathematics education. Chapel Hill, NC: Horizon Research, Inc.

Bilanich, B., 2019. Self confidence and experience. retrieved from: https://budbilanich.com/self-confidence-and-experience/

Birman, B.F., Desimone, L., Porter, A.C., and Garet, M.S. (2000). Designing professional development that works. Educational Leadership, 57(8), 28-33.

Carnegie Commission on Mathematics and Science Education. (2009). Transforming mathematics and science education for citizenship and the global economy. Carnegie Corporation of New York/Institute for Advanced Study. Retrieved from https://www.carnegie.org/media/filer public/80/c8/80c8a7bc-c7ab-4ł49 -847d-1e2966f4dd97/ccny_report_2009_opportunityequation.pdf

Darling-Hammond, L., Hyler, M. E., Gardner, M. (2017). Effective teacher professional development. Palo Alto, CA: Learning Policy Institute. Retrieved from: 
https://learningpolicyinstitute.org/sites/default/files/product-files/Effectiv e Teacher Professional Development REPORT.pdf

Davis, V. (2015). 8 top times for highly effective pd. Edutopia. George Lucas Educational Foundation. Retrieved from: https://www.edutopia.org/blog/top-tips-highly-effective-pd-vicki-davis

Explorelearning, 2019. Explorelearning Gizmos: Math and Science Simulations, Retrieved November 2019 from: https://www.explorelearning.com

Heck, D.J., Banilower, E.R., Weiss, I.R., Rosenberg, S.L. (2008). Studying the Effects of professional development: The case of the NSF's local systemic change through teacher enhancement initiative. Journal for Research in Mathematics Education, 39, 112-152. Retrieved from: https://services.lib.mtu.edu:2091/stable/30034894?sid=primo\&origin=cr ossref\&seq=1\#metadata info tab contents

Kennedy, M. M. (1979). Generalizing from single case studies. Evaluation quarterly, 3(4), 661-678.

Lauer, P.A., Christopher, D.E., Firpo-Triplett, R., Buchting, F. (2014). The impact of short term professional development on participant outcomes: A review of the literature. Professional Development in Education, 40:2, 207-227, DOI: 10.1080/19415257.2013.776619

Loucks-Horsley, S., Hewson, P. W., Love, N., Mundry, S., \& Stiles, K.E. (2010). Designing professional development for teachers of science and mathematics. Thousand Oaks, CA: Corwin Press. Retrieved 
from:

http://services.lib.mtu.edu:5838/ehost/ebookviewer/ebook/bmxlYmtfXz Q3MDUzMF9fQU41?sid=13cb02de-e2f2-45a3-9b1b-9d9d909ecd3a@ sdc-v-sessmgr01\&vid=0\&format=EK\&lpid=nav 04\&rid=0

MTTC Study Guides, Pearson Education Incorporated, 2019, Retrieved from: http://www.mttc.nesinc.com/PageView.aspx?f=HTML_FRAG/GENRB_ PrepStudyGuide.html

Mundry, S. \& Loucks-Horsley, S., (1999). Designing professional development for science and mathematics teachers: Decision points and dilemmas. National Institute for Science Education Brief, 3(1). Retrieved from: www.wcer.wisc.edu/nise

National Research Council. (2012). A framework for K-12 science education: Practices, crosscutting concepts, and core ideas. Committee on a conceptual framework for new K-12 Science education standards. Board on Science Education, Division of Behavioral and Social Sciences and Education. Washington, DC: The National Academies Press.

NGSS Lead States. 2013. Next Generation Science Standards: For States, By States. Washington, DC: The National Academies Press.

NGSS Lead States. 2013. Next Generation Science Standards: For States, By States (HS.Engineering Design). Washington, DC: The National Academies Press. Retrieved from:

https://www.nextgenscience.org/topic-arrangement/hsengineering-desi gn 
Reiser, B. J. (2013, September). What professional development strategies are needed for successful implementation of the Next Generation Science Standards. In Paper written for the Invitational Research Symposium on Science Assessment (Vol. 24, p. 25).

(C) Skills You Need. 2019. Building confidence. Retrieved from: https://www.skillsyouneed.com/ps/confidence.html

State of Michigan. (2019). Professional development workshops. Retrieved from:

http://www.michigan.gov/som/0,4669,7-192-2993932383-293787--,00 $\underline{. h t m l}$

State of Michigan. Test for Michigan teacher certification. Retrieved from: http://www.mttc.nesinc.com/Ml_viewSG_opener.asp

Stein, M.K., Smith, M.S., \& Silver, E.A. (1999). The development of professional developers: Learning to assist teachers in new settings in new ways. Harvard Educational Review, 69(3), 237-269. Retrieved from: http://hub.mspnet.org/index.cfm/9237

TeachEngineering, 2018. Investigating contact angle. Retrieved from: https://www.teachengineering.org/activities/view/duk surfacetensionun it act3

Wei, R. C., Darling-Hammond, L., Andree, A., Richardson, N., Orphanos, S. 
(2009). Professional learning in the learning profession: A status

report on teacher development in the United States and abroad.

Dallas, TX. National Staff Development Council. Retrieved from:

https://learningforward.org/docs/default-source/pdf/nsdcstudytechnicalr eport2009.pdf

Wilson, S. M. (2013). Professional development for science teachers. Science, 340(6130), 310-313. 


\section{Appendix A}

HS ETS Documents from: https://www.nextgenscience.org/topic-

arrangement/hsengineering-design

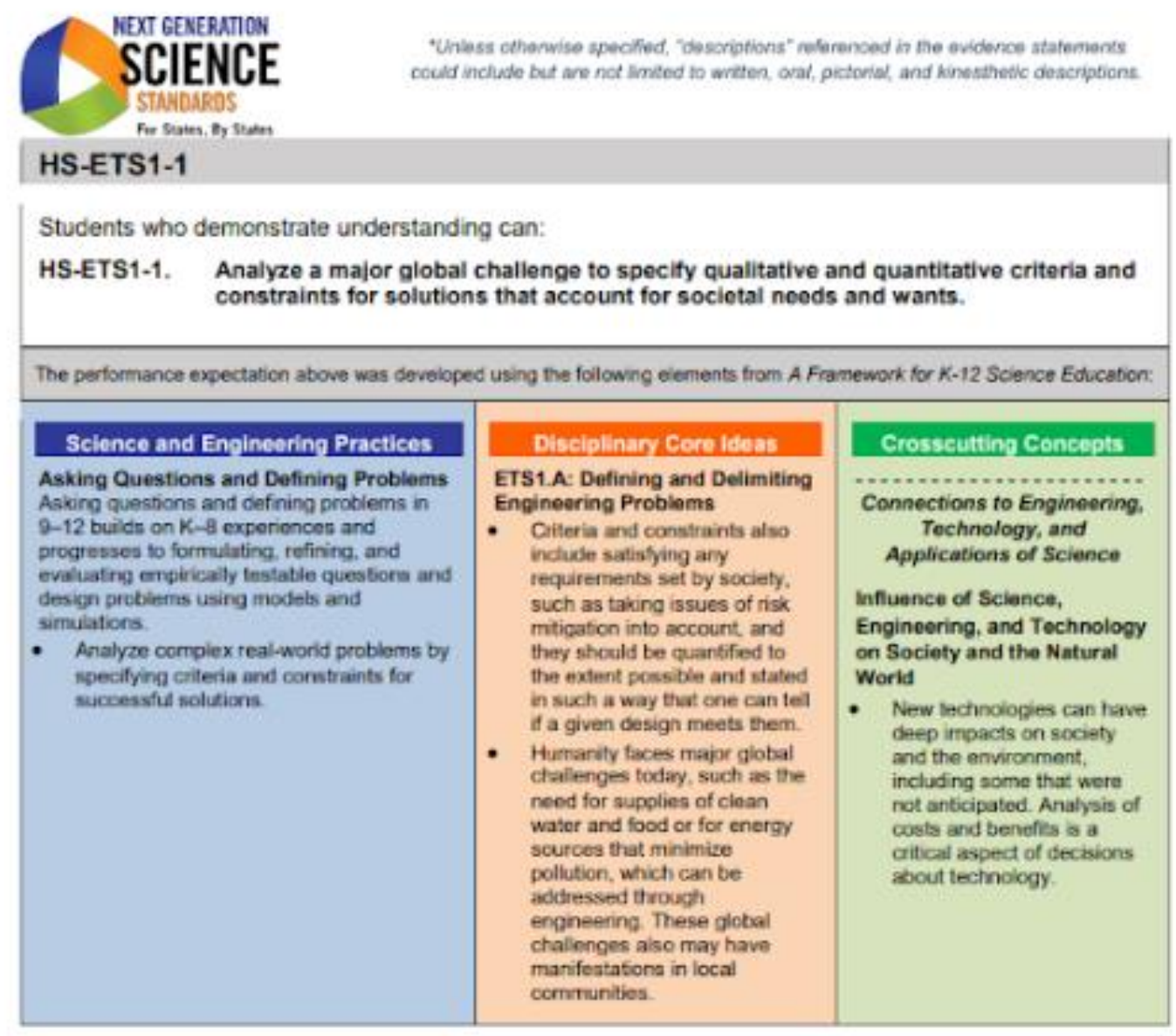

Observable features of the student performance by the end of the course:

1 Identifying the problem to be solved

a Students analyze a major global problem. In their analysis, students:

i. Describe" the challenge with a rationale for why it is a major gobal challenge;

ii. Describe*, qualitatively and quantitatively, the extent and depth of the problem and its major consequences to society and/or the natural world on both global and local scales if it remains unsolved; and

ii. Document background research on the problem from two or more sources, including research journals.

2 Defining the process or system boundaries, and the components of the process or system

a In their analysis, students identify the physical system in which the probiem is embedded. including the major elements and relationships in the system and boundaries so as to clarify what is and is not part of the problem.

b In their analysis, students describe* societal needs and wants that are relative to the problem (e.g., for controlling $\mathrm{CO}_{2}$ emissions, societal needs include the need for cheap energy).

3 Defining the criteria and constraints

a Students specify qualitative and quantitative criteria and constraints for acceptable solutions to the problem. 


\section{Coscumana}

STHDADOS

for Futes, thy state

\section{HS-ETS1-2}

Students who demonstrate understanding can:

HS-ETS1-2. Design a solution to a complex real-world problem by breaking it down into smaller, more manageable problems that can be solved through engineering.

The pertormance expectaticn above was developed using the folowing elements from $A$ Franework for $K$ - 12 Soince Edication:

Science and Enpineerine Practices

Constnucting Explanations and Designing Solutions

Constructing explanations and designing solutions in $9-12$ builds on $K-8$ experiences and progresses to explanations and designs that are supported by multiple and independent student-oenerated sources of eviderice consistent with scierkifie ideas, principles and theorien.

- Design a solubion to a conrplex reas-worid problern based an sciertific knowledge, student-generated sources of evidence. prioritized critena, and tradectf considerations.

\section{Disciplinary Core Idcas}

ETS1.C: Optimizing the Design Solution

- Criteria may need to be troker down into simpler ones that can be approached systerratically. and decisions about the priarity of cortain critoria ovar others (tradeof:s) may be needed.

\section{Crosscutting Concepts}

Observable features of the student porformance by the end of the course:

\begin{tabular}{l|ll}
\hline 1 & Using scientific knowledge to generate the design solution
\end{tabular}

a Students restate the original complex problem into a finite set of two or more sub-problems (in writing or as a diagram or flow chart).

b For at least one of the sub-problems, students propose two or more solutions that are based on student-generated data and/or scientific information from other sources.

c Students describe* how solutions to the sub-problems are interconnected to solve all or part of the larger problem.

2 Describing criteria and constraints, including quantification when appropriate

a Students describe ${ }^{*}$ criteria and constraints for the selected sub-problem.

b Students describe* the rationale for the sequence of how sub-problems are to be solved, and which criteria should be given highest priority if tradeoffs must be made. 
"Uniess otherwise specilied, "descriptions" referenced ia the evidence staferneris could include but are nct limited to wrten, oral, pictorid, and kinesthetic descrintions.

HS-ETS1-3

Students who demonstrate understanding can:

HS-ETS1-3. Evaluate a solution to a complex real-world problem based on prioritized criteria and trade-offs that account for a range of constraints, including cost, safety, reliability, and aesthetics as well as possible social, cultural, and environmental impacts.

The performance expectation above was developed using the folowing elements from $A$ Framework for $K-12$ Science Echicaticn:

Scionco and Engincoring Practicos

Constructing Explanations and Designing Solutions

Constructing explarstions send designimg solutions in 9-12 bulds on $\mathrm{K}-8$ experiences and progresses to explanations and desigss that are supported by multiple and

independent student-generaled sources of evidence cons stent with scientific idests principles and theories

- Evaluate a solution to a complex realworkd problem, based on scierafic knowledge, student-generated souaces of evidence prionitized criteria, and tradeoff considerations.

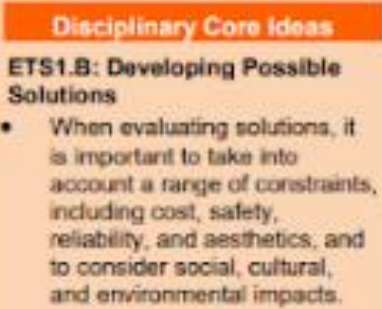

Crosscutting Concopts

.

Connections to Engineering.

Technology, and Applications of Science

Influence of Science, Engineering, and Technology on Society and the Natura! World

- New technolocies can have deep insacts on society and the environiment including some that were not anticipated. Analysis of costs and benefits is a critical aspect of decisions about techinolowy.

Observable features of the student performance by the end of the course:

1 Evaluating potential solutions

a In their evaluation of a complex real-world problem, students:

i. Generate a list of three or more realistic criteria and two or more constraints, including such relevant factors as cost, safety, reliability, and aesthetics that specifies an acceptable solution to a complex real-world problem;

i. Assign priorities for each criterion and constraint that allows for a logical and systematic evaluation of alternative solution proposals:

ii. Analyze (quantitatively where appropriate) and describe" the strengths and weaknesses of the solution with respect to each criterion and constraint, as well as social and cultural acceptability and environmental impacts:

iv. Describe* possible barriers to implementing each solution, such as cultural, economic, or other sources of resistance to potential solutions; and

v. Provide an evidence-based decision of which solution is optimum, based on prioritized criteria, analysis of the strengths and weaknesses (costs and benefits) of each solution, and barriers to be overcome.

2 Refining and/or optimizing the design solution

a In their evaluation, students describe" which parts of the complex real-worid problem may remain even if the proposed solution is implemented. 


\section{Bsinace}

HS-ETS1-4

Students who demonstrate understanding can:

HS-ETS1-4. Use a computer simulation to model the impact of proposed solutions to a complex real-world problem with numerous criteria and constraints on interactions within and between systems relevant to the problem.

The performance expectaticn above was doveioped using the following eiements from A Franework for $K$ - 12 Science Education:

Sclence and Engineering Practices Using Mathematies and Computational Thinking

Mathematical and computational thinking in $9-12$ bullds on $K-8$ experiencos and progresses lo using alyetraic thinking and analysis, a range of linear and noritineat functions incluting trigoncenetric functions, exponentials and logarthms, and computational tools for statistical anaysis to analyze, represent, and model data. Simple computational simulations are creiced and used based on mathernaticat modelt of basic assumpticne.

- Use ruathematical models andior computer simulations to precict the effects af a design solution on systerns andioc the interactions between systems

\section{Disciplinary Corcidoas}

ETS1.B: Developing Possible Solutions

- Both physical models and computers can be used in various ways to aid in the engineering design process Computers are useful for 3 variaty $d$ purposes, such as rurning simudasions to test different ways of solving a problem or to see which one is moet efficient or coonomical; and in making a persuasive presentation to a client about how a given design wil meet his or her needs.
Crosscutting Concepts Systems and System Nodals

- Models (e.g, physical, mathematical compuder models) can be used to simulate systerns and interactions - including energy, metter, ard information flows - whin and between systems at different scales

Observable features of the student pertormance by the end of the course:

1 Representation

a Students identify the following components from a given computer simulation:

i. The complex real-world problem with numerous criteria and constraints;

ii. The system that is being modeled by the computational simulation, including the boundaries of the systems;

iii. What variables can be changed by the user to evaluate the proposed solutions, tradeoffs, or other decisions; and

iv. The scientific principle(s) andior relationship(s) being used by the model.

2 Computational Modeling

a Students use the given computer simulation to model the proposed solutions by

i. Selecting logical and realistic inputs; and

ii. Using the model to simulate the effects of different solutions, tradeoffs, or other decisions.

3 Analysis

a Students compare the simulated resulis to the expected results

b Students interpret the resuits of the simulation and predict the effects of the proposed solutions within and between systems relevant to the problem based on the interpretation.

c Students identify the possible negative consequences of solutions that outweigh their benefits

d Students identify the simulation's limitations. 


\section{Appendix B Training Agenda}

NGSS ETS Implementation Training

Agenda for May 17, 2018

Greenville High School Science Department

\section{Introduction}

My credentials: My interest in engineering came about as a result of my experiences teaching physics and coaching Science Olympiad. I like the practical, mechanical applications of physics (not so much into the theoretical, though I do find it fascinating). As my students required more help than I could often give in engineering-related events, I started looking for opportunities to learn more about it. I was hoping to find something that would also help in the eternal quest for certificate renewal credits! My search led me to an engineering course for teachers offered as a two week intensive class during the summer by Michigan Tech. It was mostly grant funded, which made it more appealing, though no less intimidating!

The rest is history. I found the content totally cool - it lined right up with my interests, and I could see great potential for improving how I taught physics by weaving in engineering. During the class I learned that MTU had a masters program - one that finally met my criteria and correlated with my personal interests as well. A year later I submitted my application to pursue my Masters in Applied Science and Mathematics. I am now one research project and one class from completing the degree. It has been a challenging 10 years since 2015, (joke) but I'm almost there!

If you were hoping the engineering content in NGSS was included in 7 Science and Engineering Practices, I'm here to destroy those hopes. The good news? The ETS standards are the same for ES, LS, and PS!

Schedule for the Day:

Session $1 \quad$ 7:30 - 9:00 Unpacking ETS PE's Tech Lab 515

Session 2

9:00 - 10:00 (2nd Hour Honors 9 Physics)

Room 510

Learning Lab HS - ETS1-3 Objectives/Guiding Questions

10:00 - 11:30 Learning Lab Debriefing

Session $3 \quad 12: 30-1: 30 \quad$ Search for Simulations

Session $4 \quad 1: 30-2: 30 \quad$ Lesson Development/Brainstorming

Challenge ex. Flinn Biofuel STEM Design 


\section{Session 1: Unpacking the Standards}

1) Read the Framework narrative for the first ETS PE (Ch 8 Handout provided)

- Mark it up - underline points that stand out to you or that you'd like to ask questions or talk about.

- Think about some global challenges you might already bring up in your lessons - can they be expanded upon?

2) Check out the evidence statements. (NGSS Handout provided)

- Is there clarifying language that helps you understand what to do?

- Does it help narrow down the big ideas?

3) Look at previous grade level expectations in the Framework narrative.

- What are some things you may need to cover in case your students were not exposed to the standards already?

- Is there vocabulary you/they need to be familiar with?

4) Discussion - What did you learn? What are you still unsure about? What should

$$
\text { our/your next step be? }
$$

Displayed on Overhead Slides (one at a time, as the group went through them):

HS-ETS 1-1

Analyze a major global challenge to specify qualitative and quantitative criteria and constraints for solutions that account for major societal needs and wants.

HS-ETS 1-2

Design a solution to a complex real-world problem by breaking it down into smaller, more manageable problems that can be solved through engineering.

HS-ETS 1-3

Evaluate a solution to a complex real-world problem based on prioritized criteria and trade-offs that account for a range of constraints, including cost, safety, reliability, and aesthetics as well as possible social, cultural, and environmental impacts.

HS-ETS 1-4

Use a computer simulation to model the impact of proposed solutions to a complex real-world problem with numerous criteria and constraints on interactions within and between systems relevant to the problem. 


\title{
Session 2: Learning Lab
}

\author{
Learning Lab Note Sheet
}

Please jot down your observations with regard to the following.

Student Engagement

Teacher Instruction

ETS1-3 Strategy 


\section{Session 3: Search for Simulations}

Partner with another teacher, preferably one who teaches the same core subject as you do.

Brainstorm about topics you cover in the class that are connected to some 'real world problem' that could be addressed through an engineering project.

Look online for simulations related to the topic(s) you came up with that would be worthwhile for your students and would give them the chance to see what would take place as they changed different variables related to the issue.

\section{Session 4: Kit Exploration}

Read through the activities that came with the Bio-Fuels STEM kit. Discuss how any of them could be, or could be developed into, viable engineering projects that could be used in one or more of your core classes. 
Appendix C - Pre-Training Survey

\section{Integrating the NGSS Engineering Design Standards Pre-Training Survey}

1. As of right now, how comfortable do you feel with the idea of teaching the Engineering Technology, and Applications of Science Performance Expectations in your classroom?

$\begin{array}{ccccccc}5 & 4 & 3 & 2 & 1 & 0 \\ \text { Ready to Go! } & & & & & \text { There are ETS } \\ & & & & \text { Performance expectations?! }\end{array}$

More to share about this? Please do:

2. How familiar are you with the 4 ETS Performance Expectations?

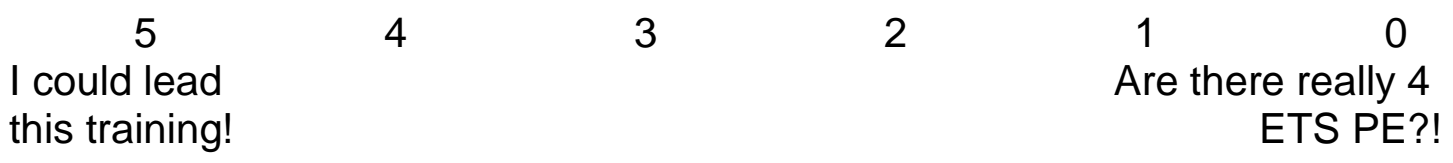

If you circled anything but 0 , please give at least a brief synopsis of what you know and how you know it (personal study?, training?, other?). Feel free to elaborate on the back of this page.

3. Give a definition for Criteria and Constraint...and please tell the difference between them!

4. What does it mean to Optimize a solution? OK to take your best shot... 
Appendix D - Post-Training Survey

Integrating the NGSS Engineering Design Standards

\section{Post P.D. Survey}

\section{A Little Demographic/Background Information...}

How many years of teaching experience do you have?

$16-20$

$21-25$

$26+$

What types of core science classes have taught in the past 3 years?

Biology

Chemistry

Physics

What is your general feeling about professional development?
5
4
3
2
1
0
Love it!
Can't get enough of it! Useless. Waste of time.

What is your general feeling about the Next Generation Science Standards?

$\begin{array}{llllcc}5 & 4 & 2 & 1 & 0 \\ \text { Excellent! } & 3 & 2 & \begin{array}{c}\text { Just another } \\ \text { swing of the } \\ \text { Much needed upgrade! }\end{array} & & \end{array}$

Were you one of the teachers in the department who were actively seeking and requesting training in the NGSS engineering standards?

yes

no

How did you feel about being required to participate in the engineering standards PD?

Great Good OK Not so bad


1. Following the PD, how would you rate your comfort level for integrating the engineering (ETS) standards into your science lessons?
5
Ready to go!
3
2
1
0
Not comfortable at all.

2. Following the $P D$, how would rate your familiarity/knowledge level with the 4 ETS performance expectations (you are not expected to have them memorized)?
5
4
3
2
1
I do not understand
I understand them and them, nor how they can see how they will fit into my science lessons.
fit into my lessons.

To familiarize you with the first two performance expectations (see below) you were asked to "unpack" the engineering standards by reading the Framework narrative (NRC, 2012) and then brainstorm with your colleagues to come up with ideas for 'complex real-world problems' you could use to help you integrate the engineering standards into your science class. You were also asked to discuss how you might break the problem down into smaller 'chunks' to make it do-able within a reasonable time frame.

HS-ETS 1-1

Analyze a major global challenge to specify qualitative and quantitative criteria and constraints for solutions that account for major societal needs and wants.

\section{HS-ETS 1-2}

Design a solution to a complex real-world problem by breaking it down into smaller, more manageable problems that can be solved through engineering.

3. How well did this session increase your confidence level for integrating the ETS (engineering) standards?
5
4
3
2
somewhat
1
0

significantly

4. How well did this session increase your knowledge of the engineering standards?

5

significantly
4

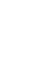

3

somewhat
2

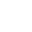


In the Learning Lab session, you observed physics students evaluating three possible solutions to a real-world problem (see PE below) related to generating electricity for runway lights using only local resources available on a remote island. The students developed a Pugh Decision Matrix, using the criteria and constraints of the original design project, to determine which solution was the best fit.

\section{HS-ETS 1-3}

Evaluate a solution to a complex real-world problem based on prioritized criteria and trade-offs that account for a range of constraints, including cost, safety, reliability, and aesthetics as well as possible social, cultural, and environmental impacts.

5. How well did this session increase your confidence to integrate the ETS standards?
5
4
3
2
1
somewhat
not at all

significantly

6. How well did this session increase your knowledge of the engineering standards?

$\begin{array}{ccllll}5 & 4 & 3 & 2 & 1 & 0 \\ \text { significantly } & & \text { somewhat } & & & \text { not at all }\end{array}$

During the final session of the $P D$, you partnered up with a colleague and were given time to explore computer simulations that could be used by your students to "model the impact of proposed solutions" to a real-world problem you could use.

\section{HS-ETS 1-4}

Use a computer simulation to model the impact of proposed solutions to a complex real-world problem with numerous criteria and constraints on interactions within and between systems relevant to the problem.

7. How well did this session increase your confidence to integrate the ETS standards?

5

significantly
4

43

somewhat
2

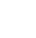

1

not at all 
8. How well did this session increase your knowledge of the engineering standards?

5

significantly
4

3

somewhat
2

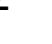

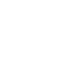

0

not at all 


\section{Appendix E - Follow Up Interview}

\section{Post PD Interview}

Protocol - Interviews will take place at the time and location chosen by the participants. Possibilities are the school, a local restaurant, a front porch, outdoors, or wherever is most convenient and comfortable for them. Interviews will be audio recorded.

0. On the Post-PD survey you indicated that your general feelings about PD are ?.

Could you elaborate on that? What has been the best type of PD you've experienced? What has been the worst?

00. When asked about your opinion about the NGSS, you indicated _?. Why?

The Pre- and Post-PD surveys asked questions about your confidence level and knowledge level regarding the implementation of the engineering standards of NGSS. I'd like to dive deeper into your responses to get a more complete picture or your personal experience before, during, and after the $P D$.

1. On a pre-PD survey question asking how confident you felt about integrating the engineering standards using a scale of 0 to 5 , with zero being "There are ETS PE's?!" and five being "Ready to Go!" you rated yourself at a_?. On the post-PD survey you gave yourself $a_{-}$?. Can you tell me more about this change/or lack of change in your confidence?

2. On a pre-PD survey question asking how knowledgeable you felt about integrating the engineering standards you rated yourself at a_? . On the post-PD survey you gave yourself a_? . Can you explain this change/or lack of change in your knowledge level?

3. On the post-PD survey you indicated that the 'unpacking of the standards' session, where we read through the Framework narratives was _? helpful for increasing your confidence, and_?_helpful for increasing your knowledge.

Could you expand upon those responses? Perhaps give examples of what was or wasn't helpful about the activity. *Invite them to answer separately about confidence and knowledge, making sure to address both. 
4. On the post-PD survey you indicated that the Learning Lab session, where you observed how the physics class addressed one of the standards was _? helpful for increasing your confidence, and _? _ helpful for increasing your knowledge.

Could you explain those responses? Perhaps give examples of what was or wasn't helpful about the activity.

5. On the post-PD survey you indicated that the 'finding computer simulations' session, where we partnered up and searched for ideas to fit our real world problem suggestions was _? helpful for increasing your confidence, and_?_helpful for increasing your knowledge.

Could you explain those responses? Perhaps give examples of what was or wasn't helpful about the activity.

9. Have you had the opportunity to integrate an engineering design project into your core science class yet?

yes no

10. If the answer to question 9 was yes...

Can you briefly describe the project your students did?

How did it go?

Would you change anything based on the PD experience?

Do you have a written lesson description/plan that you would be willing to share with me?

If the answer to question 9 was no...

Can you suggest what obstacles have kept you from being able to integrate the engineering performance expectations yet?

Do you have any in mind that you'd like to use but didn't get the chance to do so yet?

11. Have you added to your engineering arsenal since the PD? I am interested to know if you've had any training since then that helped you. Have you found any websites that gave you really good ideas? What else may have affected your confidence and/or knowledge since then?

12. Have you experienced, or can you think of something involved in planning and implementing an engineering design project were not helped by the PD experience - is there something more you wish we had covered or spent more time on - or could even base a follow up PD on? 
13. How do you think PD should be conducted? What are some ideas for planning a really meaningful training experience?

14. Is there anything else you can add that you think is relevant to this study? 